\title{
Model-based assessment for human inhalation exposure risk to airborne nano/fine titanium dioxide particles
}

\author{
Chung-Min Liao*, Yu-Hui Chiang, Chia-Pin Chio \\ Department of Bioenvironmental Systems Engineering, National Taiwan University, Taipei, 10617, Taiwan, ROC
}

\section{A R T I C L E D A T A}

Article history:

Received 10 November 2007

Received in revised form

17 September 2008

Accepted 19 September 2008

Available online 26 October 2008

Keywords:

Titanium dioxide

Nanoparticles

Lung

Risk

Particle surface area

\begin{abstract}
A B S T R A C T
This paper proposed a model-based approach to assess inhalation risk levels to manufacturing workers in titanium dioxide $\left(\mathrm{TiO}_{2}\right)$ production factories. The risk levelbased analytical schemes were present for investigations of job-related airborne nano/fine $\mathrm{TiO}_{2}$ dust exposures. A Hill model was used to reconstruct dose-response function based on data from rats exposed by chronic inhalation to poorly soluble fine and nanosized particles. A physiologically based lung model was used to predict surface area-based $\mathrm{TiO}_{2}$ burdens in alveolar surface and interstitial granuloma, respectively. The exposure effect was characterized by polymorphonuclear leukocytes (PMN) elevation effect on lung surface and lung tumor proportion on interstitium. Combining laboratory, field, and modeling results, two major findings were proposed to the current epidemiological studies: (i) the estimated median effective surface area-based $\mathrm{TiO}_{2}$ lung burden (EC50) for PMN elevation effect is $0.11 \mathrm{~m}^{2} \mathrm{~g}^{-1}$ lung (95\% CI: 0.04-0.2) and EC50 for lung tumor proportion is $1.15 \mathrm{~m}^{2} \mathrm{~g}^{-1}$ lung (95\% CI: 0.65-1.89) and (ii) the estimates of risk curves are the pivotal results for public policy. The results demonstrate that packers in US factories have approximately 85.77 fold (95\% CI: 63.84-94.33) of standard PMN counts of $10^{6}$, whereas 86.97 fold (95\% CI: 66.72-94.54) for surface treatment workers in EU factories at risk of 0.5 . The lung had approximately $45 \%$ (95\% CI: $15 \%-54 \%$ ) tumor proportion for packers in US factories, whereas $48.19 \%$ (95\% CI: $20-$ $53.79 \%$ ) for surface treatment workers in EU factories at risk of 0.5 . The findings point out that dry/wet treatment and ore handlers in US and maintenance mechanics in EU factories were unlikely to pose substantial lung cancer risks.
\end{abstract}

() 2008 Elsevier B.V. All rights reserved.

\section{Introduction}

International Agency for Research on Cancer (IARC) has recently classified titanium dioxide $\left(\mathrm{TiO}_{2}\right)$ as possibly carcinogenic to humans (Group 2B) (IARC, 2006). IARC working group concluded that the epidemiological studies on $\mathrm{TiO}_{2}$ provided inadequate evidence in humans for the carcinogenicity, whereas results from studies of inhalation and intratracheal instillation provided sufficient evidence in experimental animals for the carcinogenicity of $\mathrm{TiO}_{2}$ (Baan et al., 2006).

$\mathrm{TiO}_{2}$ accounts for $70 \%$ of the total production volume of pigments worldwide (Baan et al., 2006). The $\mathrm{TiO}_{2}$ varied not only in particle size but also in surface areas with hydrophilic and hydrophobic surface properties. Fine and nanosized $\mathrm{TiO}_{2}$ (nano- $\mathrm{TiO}_{2}$ ) particles are typically $200-300 \mathrm{~nm}$ and $10-50 \mathrm{~nm}$ in diameter, respectively; with the average specific surface areas (SSA) of 10 and $50 \mathrm{~m}^{2} \mathrm{~g}^{-1}$ (Höhr et al., 2002). Nano-TiO ${ }_{2}$ is used in sunscreens and plastics to block ultraviolet light and as catalysts. High exposures occur in $\mathrm{TiO}_{2}$ production during packing, milling, site cleaning, and maintenance. Berges et al. (2007) indicated that at the bin filling station total number concentrations of $\mathrm{TiO}_{2}$ between 15,000 and 156,000 particles $\mathrm{cm}^{-3}$ appeared with maxima varying between 20 and $30 \mathrm{~nm}$ with the primary particle diameters ranging from 25-100 nm.

\footnotetext{
* Corresponding author. Tel.: +8862 2363 4512; fax: +886 223626433.

E-mail address: cmliao@ntu.edu.tw (C.-M. Liao).
} 
National Institute for Occupational Safety and Health (NIOSH) (NIOSH, 2005) suggested that exposure limits for fine and nano- $-\mathrm{TiO}_{2}$ are recommended to be 1.5 and $0.1 \mathrm{mg} \mathrm{m}^{-3}$, respectively, as time-weighted average (TWA) concentration for up to $10 \mathrm{~h} \mathrm{~d}^{-1}$ during a 40 -h work week. Kuempel et al. (2006) used a rat-based lung dosimetry model to estimate airborne $\mathrm{TiO}_{2}$ exposure guidelines (8-h TWA) over a 45-year working lifetime associated with $0.1 \%$ excess risk of lung cancer based on lower 95\% confidence limit of benchmark dose, suggesting that human-equivalent exposure concentrations for fine $\mathrm{TiO}_{2}$ ranges from $0.68-1.3 \mathrm{mg} \mathrm{m}^{-3}$ and 0.073 $0.14 \mathrm{mg} \mathrm{m}^{-3}$ for nano- $\mathrm{TiO}_{2}$.

Three published epidemiologic studies had provided information on the potential carcinogenicity of airborne $\mathrm{TiO}_{2}$ dust in humans (Chen and Fayerweather, 1988; Fayerweather et al., 1992; Boffetta et al., 2001). Taken together, the major epidemiological cohort studies (Fryzek et al., 2003; Boffetta et al., 2004) indicated that airborne $\mathrm{TiO}_{2}$ dust exposures and health effects were unlikely to pose any substantial risk to public health. Yet, all the studies had methodological and epidemiological limitations and provided no clear evidence of elevated risks of lung cancer mortality and morbidity among those workers exposed to $\mathrm{TiO}_{2}$ dust (NIOSH, 2005; IARC, 2006).

Large gaps, however, remain in the knowledge base that is needed to conduct quantitative risk assessment for inhaled nanoparticles (NPs). NPs are usually defined as particle with an aerodynamic diameter less than $100 \mathrm{~nm}$. A comprehensive mechanistic understanding has been lacking for prediction of airborne NPs on human health effects (Maynard et al., 2006; Maynard and Aitken, 2007). NPs have been postulated to affect cardiopulmonary systems and can also exacerbate lung inflammation (Nel, 2005; Nel et al., 2006). Lung inflammatory response is typically measured experimentally with the surrogate measure of the number of polymorphonuclear leukocytes (PMNs) or called neutrophils found in the bronchoavlveolar lavage (BAL) at some time after exposure (Höhr et al., 2002; Stoeger et al., 2006; Wittmaack, 2007). NPs are reportedly able to penetrate deeply into the respiratory tract and have a larger surface area per unit mass than do larger particles, resulting in a greater inflammatory response (Nemmar et al., 2002; Nel, 2005). Furthermore, NPs can also translocate from the lung into the circulation (Nemmar et al., 2002, 2003).

Relevant evidence suggests that NPs surface area matters more than particle mass for quantifying lung inflammatory response to NPs exposure, supporting the surface area is the dose measurement that best predicts pulmonary toxicity (Donaldson and Tran, 2002; Donaldson et al., 2004; Nel, 2005; Nel et al., 2006; Oberdörster et al., 2005; Wittmaack, 2007). Inoue et al. (2006) demonstrated that not only the size effects of NPs on acute lung inflammation but also the effects of their surface area and/or the effects of their number on inflammation. It suggests that inhalation studies should provide better understanding of the effects of the NPs on acute lung inflammation by using uniform surface area and particle numbers. Given the importance of $\mathrm{TiO}_{2}$ as industrial and commercial agents and the relative scarcity of data on human carcinogenicity, this study conducted a model-based assessment to quantify the inhalation exposure risks for workers in the $\mathrm{TiO}_{2}$ production factories. To date, there are a number of tentative risk assessment/management frameworks for NPs have been initiated (NIOSH, 2005; Oberdörster et al., 2005; Maynard et al., 2006; Tsuji et al., 2006; Maynard and Aitken, 2007). Although it is possible that $\mathrm{TiO}_{2}$ may create toxic effects, there are currently no conclusive data or scenarios that indicate that these effects will become a major problem. At the same time, it can no longer postpone safety evaluations of $\mathrm{TiO}_{2}$. However, a proactive approach is required and potential health risks from exposure to airborne $\mathrm{TiO}_{2}$ dust must be also understood and minimized.

The objective of this paper was to develop a quantitative risk assessment model for predicting the potential impact of airborne $\mathrm{TiO}_{2}$ dust on the human health. This study reanalyzed published data of airborne $\mathrm{TiO}_{2}$ measurements during manufacturing activities and incorporated a compartmentalized physiologically based lung model to estimate the $\mathrm{TiO}_{2}$ burden in lung cells. Predicted lung cell burdens were combined with dose-response relationships derived from published animal model to assess risk endpoints. To determine overall uncertainties in predicted risks, the uncertainties resulting from the assessments of exposure and dose-response were propagated through the risk characterization process using Monte Carlo (MC) analysis.

\section{Materials and methods}

The proposed risk assessment approach can be divided into four phases (Fig. 1) based on a risk assessment framework for unknown particle size distribution containing $\mathrm{TiO}_{2}$ (NIOSH, 2005) and nanomaterials (Tsuji et al., 2006) to account for human inhalation exposure risk to airborne $\mathrm{TiO}_{2}$ dust. The details are described in the subsequent sections.

\subsection{Problem formulation: quantitative published data}

There is relatively little empirical data in indoor $\mathrm{TiO}_{2}$ dust sources. Accordingly, this study must rely on data reanalysis technique together with whatever empirical data is available. Two remarkable datasets related to $\mathrm{TiO}_{2}$ dust concentrations in titanium dioxide plants in the United States (US) (Fryzek et al., 2003) and Europe (EU) (Boffetta et al., 2003, 2004), respectively (Table 1), give this study the opportunity to test all theoretical considerations of $\mathrm{TiO}_{2}$ dust exposure effects and quantify its strength. The information of particle size distributions of airborne $\mathrm{TiO}_{2}$ dust was not informed explicitly. Fryzek et al. (2003) collected nearly 2400 separate records of airborne sampling data from 1976-2000 for a wide variety of substances such as sulfuric acid mist, sulfur dioxide, hydrogen sulfide, hydrogen chloride, chloride, $\mathrm{TiCl}_{4}$, and $\mathrm{TiO}_{2}$ that obtained from the four $\mathrm{TiO}_{2}$ manufacturers. Fryzek et al. (2003) identified 914 air samples for total $\mathrm{TiO}_{2}$ dust they used in their analysis to estimate relative exposure levels among jobs titles during various time periods. Boffetta et al. (2003) collected respirable $\mathrm{TiO}_{2}$ dust exposure data from 15,017 workers employed in 11 pigment-grade $\mathrm{TiO}_{2}$ production factories in EU from Finland, France, Germany, Italy, Norway, and United Kingdom based on the periods ranging from 1927 to 1969 until 1955 to 2001. Most samples 


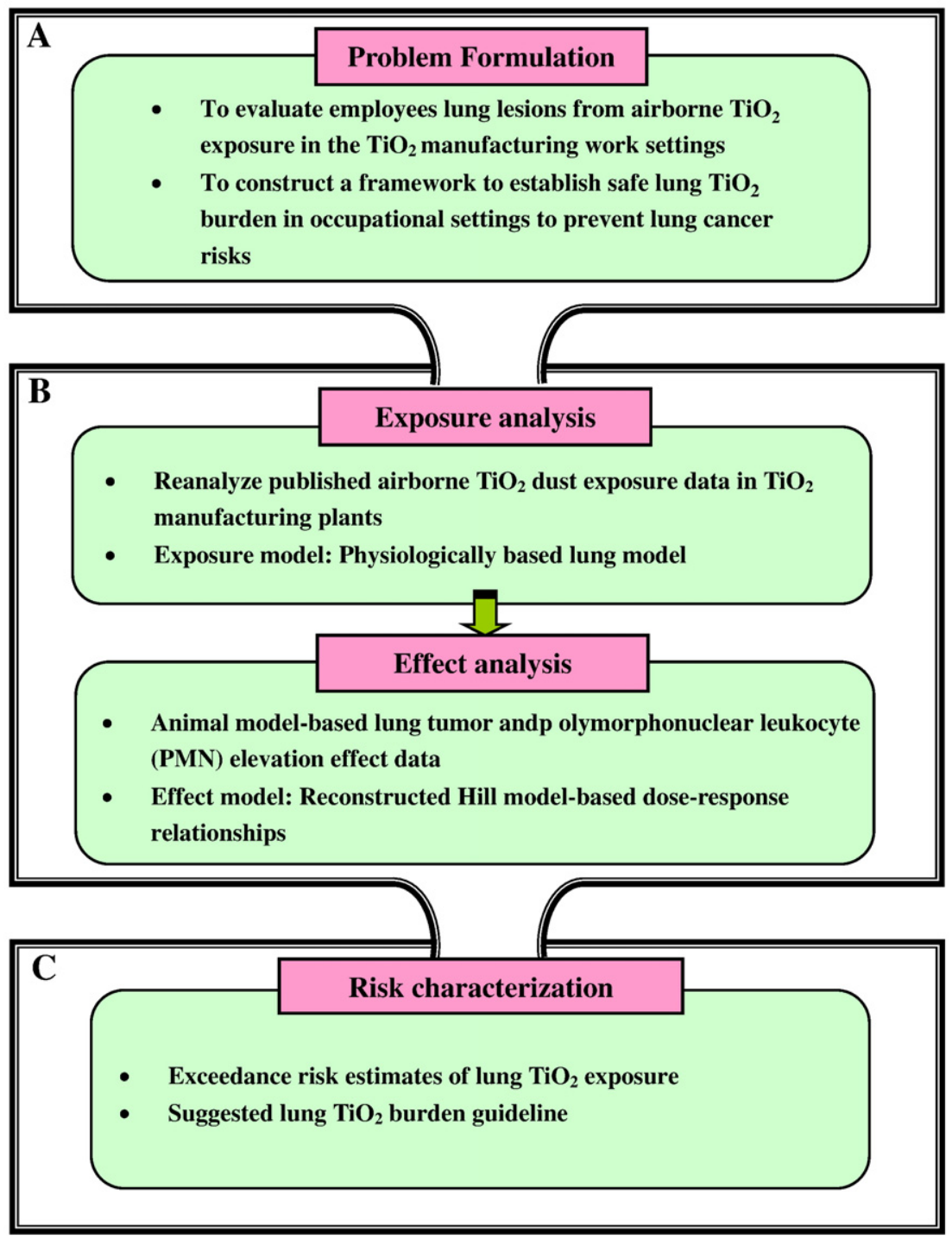

Fig. 1-Schematic representation of proposed risk assessment framework for airborne nano/fine titanium dioxide particles.

were taken as part of routine measurement programmes during the 1990s. Job categories divided into surface treatment including drying, packing, and blending, maintenance mechanics, mixed jobs, and other jobs.

The measurements from Fryzek et al. (2003) indicated that different job categories of packers, micronizers and addbacks, ore handlers, maintenance mechanics, dry and wet treatment, and other exposed jobs experienced different $\mathrm{TiO}_{2}$ dust concentrations. Fryzek et al. (2003) reported that packers, micronizers and addbacks had the highest $\mathrm{TiO}_{2}$ measured levels of $6.2 \pm 9.4 \mathrm{mg} \mathrm{m}^{-3}$, whereas ore handlers had the lowest $\mathrm{TiO}_{2}$ exposure level of $1.1 \pm 1.1 \mathrm{mg} \mathrm{m}^{-3}$. Boffetta et al. (2004) reported that the yearly averaged estimated exposure to $\mathrm{TiO}_{2}$ dust in EU factories varied from 1.0 to $0.1 \mathrm{mg} \mathrm{m}^{-3}$. The highest exposures at the factory level were in the order of $1.0 \mathrm{mg} \mathrm{m}^{-3}$, whereas average levels ranged up to $5 \mathrm{mg} \mathrm{m}^{-3}$ for individual occupational titles. The measurements from Boffetta et al. (2003) indicated that workers employed in the surface treatment area had the highest estimated yearly cumulative exposure of median $7.75 \mathrm{mg} \mathrm{m}^{-3}$ with an interquartile range
3.24-24.9 $\mathrm{mg} \mathrm{m}^{-3}$, whereas the overall median estimated cumulative exposure level was $1.98 \mathrm{mg} \mathrm{m}^{-3}$ with an interquartile range $0.26-6.88 \mathrm{mg} \mathrm{m}^{-3}$.

This study reanalyzed the measured total $\mathrm{TiO}_{2}$ dust concentrations through statistical tests. There are multiple potential sources of variability and uncertainty to be considered during distribution development for $\mathrm{TiO}_{2}$ dust concentrations in manufacturing plants from measured values. Therefore, data were log-transformed when necessary to meet the assumptions of statistical tests. All statistical analyses were conducted using Crystal Ball software (Version 2000.2, Professional Edition, Decisioneering, Inc., Denver, CO, USA).

\subsection{Exposure analysis: physiologically based lung model}

A compartmentalized physiologically based (PB) lung model developed by Tran et al. $(1999,2000,2003)$ and Kuempel et al. (2001) was used to estimate $\mathrm{TiO}_{2}$ burden in lung tissue. The $\mathrm{PB}$ lung model is capable of describing the progress over time 
Table 1 - The original data of $\mathrm{TiO}_{2}$ dust concentrations for different job categories measured in $\mathrm{TiO}_{2}$ manufacturing factories adopted from US and EU cohort studies

\begin{tabular}{lc} 
Job category & $\mathrm{TiO}_{2}$ dust concentration $\left(\mathrm{mg} \mathrm{m}^{-3}\right)$ \\
\hline US $^{\mathrm{a}}$ & \\
Packers & $6.2 \pm 9.4(n=686)^{\mathrm{b}}$ \\
Maintenance mechanics & $2.5 \pm 6.9(n=59)$ \\
Dry and wet treatment & $1.1 \pm 1.1(n=117)$ \\
Ore handlers & $2 \pm 7.6(n=21)$ \\
Other jobs & $0.6 \pm 0.9(n=31)$ \\
EU & \\
Surface treatment & $7.75(3.14-24.9)^{\mathrm{d}}$ \\
Mixed & $3.33(0.88-10.6)$ \\
Maintenance mechanics & $1.26(0.25-3.32)$ \\
Other jobs & $1.31(0-5.29)$ \\
\hline a Adopted from Fryzek et al. (2003). & \\
b Mean \pm SD and $n=$ sample number. & \\
c Adopted from Boffetta et al. (2003). \\
d Median with interquartile range in the parenthesis. \\
\hline
\end{tabular}

of the retention of particles and the alveolar macrophage (AM)-mediated clearance process in the pulmonary region associated with the particle redistribution and the overload phenomena. The PB lung model mainly divides the lung into three regions of alveolar surface, interstitium, and lymph nodes (Fig. 2A). The alveolar surface region contains four compartments (Fig. 2B): one for incoming free particles $\left(\mathrm{X}_{1}\right)$ and the other three represent mobile AMs $\left(X_{2}\right)$, decayed/ inactive AMs $\left(X_{3}\right)$, and alveolar sequestration $\left(X_{4}\right)$, respectively. On the other hand, there are also have four compartments assigned for interstitium region (Fig. 2C): one for free particles $\left(\mathrm{X}_{5}\right)$ and the other three respectively denote mobile interstitial macrophages (IMs) $\left(X_{6}\right)$, decayed/inactive IMs $\left(X_{7}\right)$, and interstitial granuloma $\left(X_{8}\right)$. From the interstitium region, some particles of free and inside IMs can be removed to the lymph nodes region that is represented by compartment $\mathrm{X}_{9}$ (Fig. 2D).

Tran et al. (2003) have described comprehensively the PB lung model framework and the essential model parameters that characterizing the model structure and function. Based on the principle of mass balance; a set of ordinary differential equations (Eqs. (1)-(9)) can be reformulated from Tran et al. (2003) with new parameter groupings to describe the dynamic behavior of PB lung model (Table 2). Table 3 summarizes the lung physiological parameters and their likely values employed in the PB lung model.

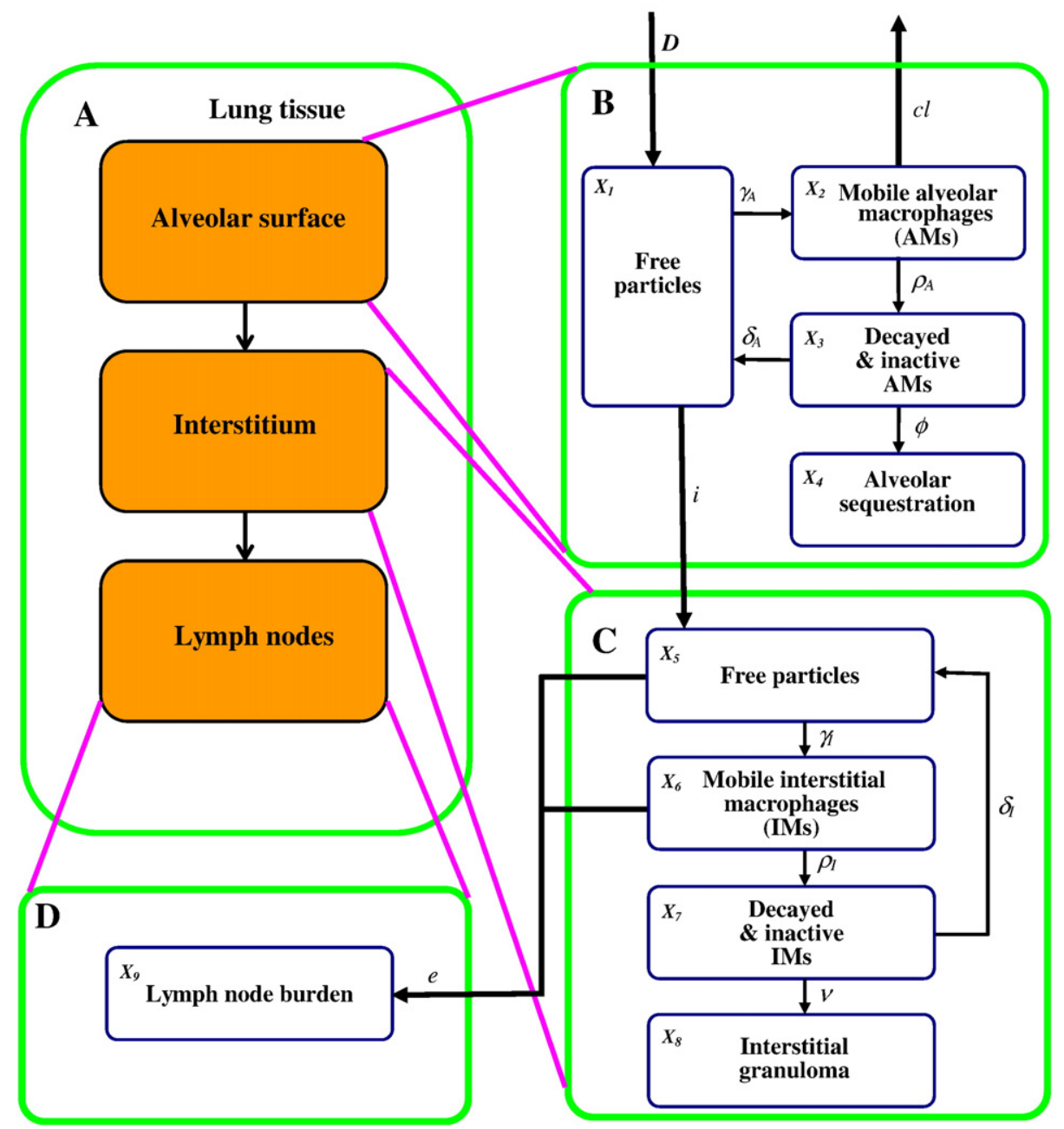

Fig. 2-Schematic representation of a compartmentalized physiologically based lung model: (A) lung tissue, (B) alveolar surface, (C) interstitum, and (D) lymph nodes. 
Table 2 - Dynamic equations used in the physiologically based lung model

$$
\begin{aligned}
& \text { Alveolar surface } \\
& \frac{d X_{1}}{d t}=D-r_{\mathrm{A}} X_{1}-\left[i_{\text {normal }} \theta\left(S_{\text {alv }}\right)+\left(1-\theta\left(S_{\text {alv }}\right)\right) i_{\text {max }}\right] X_{1}+\theta\left(S_{\text {alv }}\right) \delta_{\mathrm{A}} X_{3} \\
& \frac{d X_{2}}{d t}=r_{\mathrm{A}} X_{1}-\theta\left(S_{\text {alv }}\right) c l X_{2}-\rho_{\mathrm{A}} X_{2} \\
& \frac{d X_{3}}{d t}=\rho_{\mathrm{A}} X_{2}-\theta\left(S_{\text {alv }}\right) \delta_{\mathrm{A}} X_{3}-\left(1-\theta\left(S_{\text {alv }}\right)\right) \phi X_{3} \\
& \frac{d X_{4}}{d t}=\left(1-\theta\left(S_{\text {alv }}\right)\right) \phi X_{3}
\end{aligned}
$$

\section{Interstitium}

$\begin{aligned} \frac{d X_{5}}{d t}= & {\left[i_{\text {normal }} \theta\left(S_{\text {alv }}\right)+\left(1-\theta\left(S_{\text {alv }}\right)\right) i_{\text {max }}\right] X_{1}-\theta\left(S_{\text {inst }}\right) e X_{5}-r_{I} X_{5} } \\ & +\theta\left(S_{\text {inst }}\right) \delta_{I} X_{7}\end{aligned}$

$\frac{d X_{6}}{d t}=r_{1} X_{5}-\rho_{1} X_{6}-\theta\left(S_{\text {inst }}\right) e X_{6}$

$\frac{d X_{7}}{d t}=\rho_{\mathrm{I}} X_{6}-\theta\left(S_{\text {inst }}\right) \delta_{\mathrm{I}} X_{7}-\left(1-\theta\left(S_{\text {inst }}\right)\right) v X_{7}$

$\frac{d X_{8}}{d t}=\left(1-\theta\left(S_{\text {inst }}\right)\right) v X_{7}$

Lymphatic nodes

$\frac{d X_{9}}{d t}=\theta\left(S_{\text {inst }}\right) e\left(X_{5}+X_{6}\right)$

a Adopted from Tran et al. (2003). Abbreviations and parameter symbols: $\mathrm{D}$ : Deposited dose rate $\left(\mathrm{m}^{2} \mathrm{~d}^{-1}\right), r_{\mathrm{A}}$ : Phagocytosis rate by alveolar macrophage (AM) $\left(\mathrm{d}^{-1}\right), i_{\text {normal }}$ Normal interstitialisation rate of particle $\left(\mathrm{d}^{-1}\right), i_{\text {max }}$ : Maximum interstitialisation rate of particle $\left(\mathrm{d}^{-1}\right), \theta\left(\mathrm{S}_{\text {alv }}\right)$ : Function of alveolar surface burden that describes retardation of clearance of insoluble dust, $\delta_{\mathrm{A}}$ : Rate of particles back to alveolar surface for rephagocyosis $\left(\mathrm{d}^{-1}\right), \rho_{\mathrm{A}}$ : Transfer rate of particles from active to inactive AMs $\left(\mathrm{d}^{-1}\right)$, cl: AM-mediated clearance of particle $\left(\mathrm{d}^{-1}\right), \phi$ : Alveolar sequestration $\left(\mathrm{d}^{-1}\right), \theta\left(\mathrm{S}_{\text {inst }}\right)$ : Function of interstitium burden that describe retardation of clearance of insoluble dust, e: Removal rate of particles to lymph nods, $r_{\mathrm{I}}$ : Phagocytosis rate by interstitial macrophage (IM) $\left(\mathrm{d}^{-1}\right), \delta_{\mathrm{I}}$ : Rate of particles back to interstitium for rephagocyosis $\left(\mathrm{d}^{-1}\right), \rho_{\mathrm{I}}$ : Transfer rate of particles from active to inactive IMs $\left(\mathrm{d}^{-1}\right)$, and $v$ : Rate of formation of interstitial granuloma $\left(\mathrm{d}^{-1}\right)$.

\subsection{Effect analysis: animal-based dose-response relationships}

Experiments with animals presume that animals are good surrogates for humans and that effects detected in animals will also occur in humans. Consequently, extrapolations from high to low doses and from lifetime exposures to short-term exposures in rodents have been used to estimate risks to humans (NIOSH, 2005; Kuempel et al., 2006). All of these extrapolations to date have been undertaken by fitting statistical models to data. An assessment of the risk to human health of exposure to $\mathrm{TiO}_{2}$ dust can be derived relying on animal studies. Two rat models conducted respectively by
Oberdörster et al. (1994) and Tran et al. (1999) are used to construct the dose-response relationships between $\mathrm{TiO}_{2}$ induced PMN elevation effects and particle surface areabased $\mathrm{TiO}_{2}$ lung burdens. On the other hand, two rat models conducted by Lee et al. (1985) and Heinrich et al. (1995) were adopted to construct the dose-response relationships between lung tumor proportion and surface area-based $\mathrm{TiO}_{2}$ lung burdens.

The measured particle size distributions in laboratory $\mathrm{TiO}_{2}$-associated PMN effects rat models followed lognormal (LN) distributions of $2.1 \mu \mathrm{m}$ mass median aerodynamic diameter (MMAD) and 2.2 geometric standard deviation (GSD) for fine $\mathrm{TiO}_{2}$ and $0.8 \mu \mathrm{m}$ MMAD and $1.8 \mathrm{GSD}$ for nano- $\mathrm{TiO}_{2}$ (Tran et al., 1999), whereas 1.5-1.7 $\mu \mathrm{m}$ MMAD for fine $\mathrm{TiO}_{2}$ (Lee et al., 1985) and $0.8 \mu \mathrm{m} \mathrm{MMAD}$ and $1.8 \mathrm{GSD}$ for nano- $\mathrm{TiO}_{2}$ in lung tumor proportion rat models (Oberdörster et al., 1994).

A three-parameter Hill equation model that is commonly used in pharmacodynamic modeling was used to optimal fit the animal experimental data to reconstruct dose-response profile taking into account the pooled fine and nanosized $\mathrm{TiO}_{2}$ particles effects to human health from PMN elevation effects and lung tumor occurrence proportion. This study appropriately and carefully selected the well-analyzed related data points from NIOSH (2005). Hill equation model captures the relation between internal lung $\mathrm{TiO}_{2}$ burden and effect as

$E=\frac{E_{\max } C^{n}}{E C_{\max / 2}^{n}+C^{n}}$

where $C$ is the concentration in the receptor, $E_{\max }$ is the maximum dose effect, $\mathrm{EC}_{\max / 2}$ is the concentration that causes

Table 3 - Input lung physiological parameters used in the physiologically based lung model

Meaning and symbol

Unit Value

Alveolar surface

Phagocytosis rate by alveolar macrophage (AM): $r_{\mathrm{A}}$

Normal interstitialisation rate of particle: $i_{\text {normal }}$

Maximum interstitialisation rate of particle: $i_{\max }$

Function of alveolar surface burden that describe retardation of clearance of insoluble dust: $\theta\left(\mathrm{S}_{\text {alv }}\right)$

Rate of particles back to alveolar surface for rephagocyosis: $\delta_{\mathrm{A}}$

Transfer rate of particles from active to inactive AMs: $\rho_{\mathrm{A}}$

AM-mediated clearance of particle: $\mathrm{cl}$

Alveolar sequestration: $\phi$

$\begin{array}{ll}d^{-1} & 0.966 \\ d^{-1} & 0.0072 \\ d^{-1} & 0.4347 \\ - & 0.6 \\ & \\ d^{-1} & 0.14 \\ & \\ d^{-1} & 0.036 \\ & \\ d^{-1} & 0.0036 \\ d^{-1} & 0.14\end{array}$

Interstitium

Phagocytosis rate by interstitial macrophage: $r_{\mathrm{I}} \quad \mathrm{d}^{-1} \quad 0.966$

Function of interstitium burden that describe

- 0.6 retardation of clearance of insoluble dust: $\theta$ ( $\left(S_{\text {inst }}\right)$

Rate of particles back to interstitium

$d^{-1} \quad 0.14$

for rephagocyosis: $\delta_{1}$

Transfer rate of particles from active to inactive IMs: $\rho_{\mathrm{I}}$

Rate of formation of interstitial granuloma: $v$

$d^{-1} \quad 0.036$

$d^{-1} \quad 0.14$

Lymph nodes

Removal rate of particles to lymph nods: $e$

$d^{-1} \quad 0.0242$ 
an equal effect to half of the $E_{\max }$, and $n$ is a slope factor referred to as the Hill coefficient determining the overall shape of the curve. Hill coefficient is a measure of cooperativity. A value of $n>1$ indicates positive cooperativity.

\subsection{Risk characterization: risk model}

Effect concentration was adjusted based on concentration-time profile by using uncertainty factors as follows (USEPA, 1994),

$\mathrm{EC}_{\mathrm{a}}=\frac{\mathrm{EC}}{\mathrm{F}_{1} \times \mathrm{F}_{2} \times \mathrm{F}_{3}}$,

where $E_{a}$ is adjusted effect concentration, EC is effect concentration estimated from reconstructed Hill model-based dose-response profiles, $F_{1}$ and $F_{2}$ are uncertainty factors used to account for potential interspecies variation in response sensitivity and potential intraspecies variation in human sensitivity, and $F_{3}$ is the uncertainty factor used when a lifetime or longterm EC is desired and only a short-term EC is available. Dourson and Stara (1983) had reviewed the historical and experimental bases for uncertainty factors.

Risk at a specific target organ concentration, $C$, can be calculated as the proportion of the group expected to have that tissue concentration multiplied by the conditional probability of adverse effects, given concentration $C$. This results in a joint probability function or exceedance risk profile as

$R_{C}=P(C) P(E \mid C)$,

where $R_{C}$ is the risk at a specific concentration $C, P(C)$ is the probability of having tissue concentration $C$, and $P(E \mid C)$ is the conditional probability of the adverse effect, given tissue concentration $\mathrm{C}$. The overall expected risk for job-specific workers might be computed as the sum of the risks given the most possible prevalent exposure routes,

$R=\int_{-\infty}^{\infty} \frac{1}{\sqrt{2 \pi \sigma_{\mathrm{e}}}} \exp \left[-\frac{1}{2}\left(\left(\log C-\mu_{\mathrm{e}}\right) / \sigma_{\mathrm{e}}\right)^{2}\right] P(E \mid C) d \log C$,

where $\mu_{\mathrm{e}}$ and $\sigma_{\mathrm{e}}$ are mean and standard deviation of the logtransformed $\mathrm{TiO}_{2}$ exposures, respectively; and $R$ is the estimated fraction of the job-specific workers that is expected to suffer adverse effects.

\subsection{Uncertainty analysis}

Capturing uncertainty is a key element in risk assessment. Uncertainty arises from estimation of both exposure and effects. In order to quantify this uncertainty and its impact on the estimation of expected risk, we implement a MC simulation that includes input distributions for the parameters of the derived concentration-response function as well as for estimated exposure parameters. Ten thousand executions of the MC simulation are performed. A 95\% confidence interval (CI) for expected risk is determined on the basis of the 2.5th and 97.5th quantiles of the simulation results. A risk curve was generated from the cumulative distribution of simulation outcomes. The simulation was implemented using Crystal Ball software (Version
2000.2, Professional Edition, Decisioneering, Inc., Denver, CO, USA).

\section{Results}

\subsection{Exposure assessment}

The original data obtained from Fryzek et al. (2003) and Boffetta et al. (2003) were log-transformed appropriately to job-specific surface area-based $\mathrm{TiO}_{2}$ dust concentrations in $\mathrm{TiO}_{2}$ production factories in US and EU (Fig. 3) based on a conversion factor of $\mathrm{V}\left(\mathrm{m}^{3}\right) \times \mathrm{SSA}\left(\mathrm{m}^{2} \mathrm{~g}^{-1} \mathrm{TiO}_{2}\right) \times 10^{-3}$ where $\mathrm{V}$ is the working space volume (here we reasonably assume $\mathrm{V}=300 \mathrm{~m}^{3}$ ) and SSA is specific surface area of a typical nano- $\mathrm{TiO}_{2}$ particles (here an average SSA $=50 \mathrm{~m}^{2} \mathrm{~g}^{-1} \mathrm{TiO}_{2}$ was used) (Höhr et al., 2002). The median job-specific surface area-based $\mathrm{TiO}_{2}$ concentrations were estimated to be $0.168 \mathrm{~m}^{2}$ (95\% CI: $\left.0.0815-0.357\right), 0.042 \mathrm{~m}^{2}$ (95\% CI: $0.016-0.115), 0.026 \mathrm{~m}^{2}$ (95\% CI: $\left.0.009-0.078\right)$, and $0.04 \mathrm{~m}^{2}$ (95\% CI: 0.022-0.068), respectively, for packers, maintenance mechanics, dry/wet treatment, and ore handlers in the U.S. plants (Fig. 3A). On the other hand, for the production industry in EU, job group of surface treatment (including drying, packing, and blending) experienced the highest median surface-based $\mathrm{TiO}_{2}$ concentration (0.387 $\mathrm{m}^{2}$ with a $\left.95 \% \mathrm{CI}: 0.143-1.00\right)$ ) than those of mixed jobs (0.138 $\mathrm{m}^{2}$ (95\% CI: 0.043-0.445)), and maintenance mechanics (0.045 $\mathrm{m}^{2}$ (95\% CI: 0.012-0.154)).

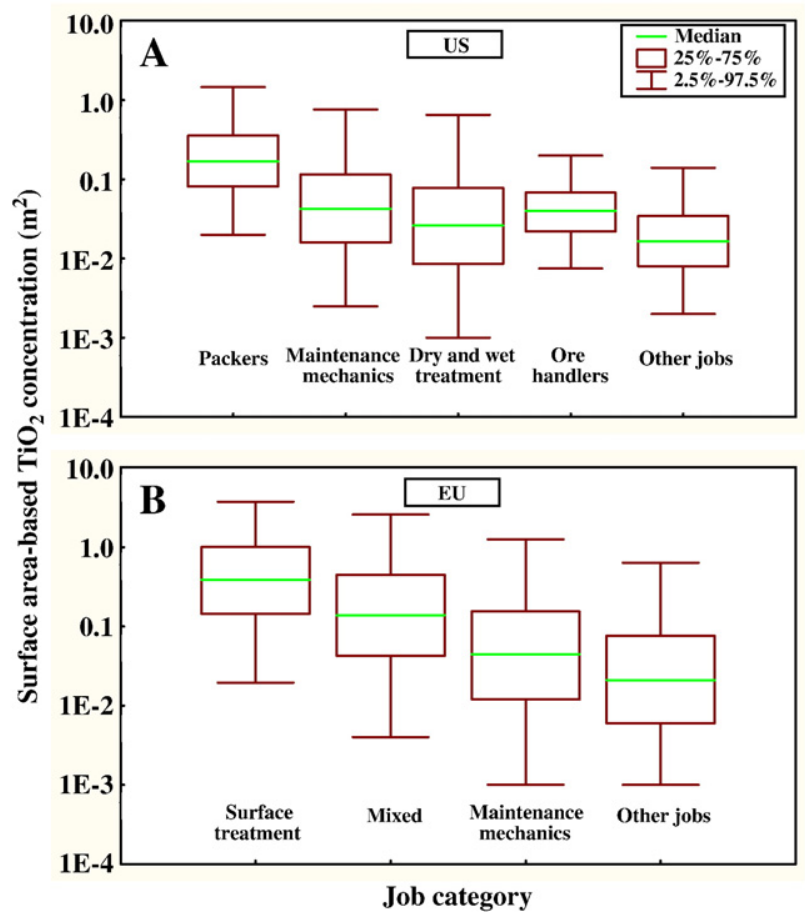

Fig. 3-Box and whisker representations of job-specific surface area-based airborne $\mathrm{TiO}_{2}$ concentrations in $\mathrm{TiO}_{2}$ production factories in (A) United States and (B) Europe. 


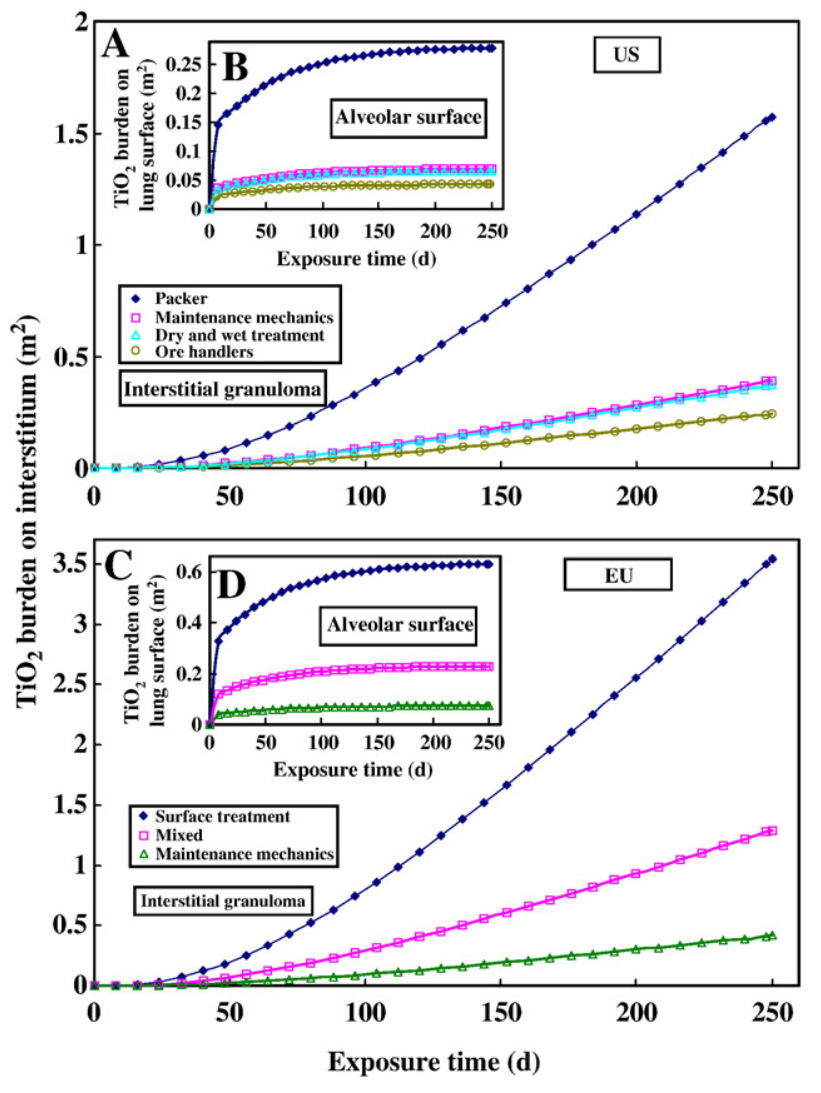

Fig. 4-Simulation of job-specific time-dependent $\mathrm{TiO}_{2}$ burdens in lung tissues of alveolar surface and interstitial granuloma for United States (A, B) and Europe (C, D) $\mathrm{TiO}_{2}$ production factories.

Fig. 4 shows the simulated time-course job-specific $\mathrm{TiO}_{2}$ burdens in lung tissue of alveolar surface and interstitial granuloma followed respirable $\mathrm{TiO}_{2}$ dust exposure shown in Fig. 3. $\mathrm{TiO}_{2}$ burdens in interstitial granuloma never approach a steady-state. The results indicate that on the day 250th, the exposure doses were estimated to be 1.75, $0.39,0.37$, and $0.24 \mathrm{~m}^{2}$, respectively, for packers, maintenance mechanics, ore handlers, and dry/wet treatment workers in US plants (Fig. 4A), whereas EU plants experienced higher interstitial granuloma $\mathrm{TiO}_{2}$ burdens in production workers (surface treatment: $3.54 \mathrm{~m}^{2}$, mixed jobs: $1.29 \mathrm{~m}^{2}$, and maintenance mechanics: $0.415 \mathrm{~m}^{2}$ ) (Fig. 4C). After a 250-day exposure, the $\mathrm{TiO}_{2}$ burdens in alveolar surface reach steady-state approximately, indicating that the manufacturing workers of packers in US and surface treatment in EU plants have the highest alveolar $\mathrm{TiO}_{2}$ burdens of 0.28 and $0.63 \mathrm{~m}^{2}$, respectively (Fig. 4B,D). Fig. 4 also demonstrates that maintenance mechanics in US and EU plants nearly have the same $\mathrm{TiO}_{2}$ burdens in alveolar surface and interstitial granuloma.

\subsection{Dose-response assessment}

The reconstructed Hill-based $\mathrm{TiO}_{2}$ dose-response profiles were shown in Fig. 5. The three-parameter Hill equation model and a
10,000 MC simulation provided an adequate fit for the animal experimental data from pooled fine and nano- $\mathrm{TiO}_{2}$ particles effects on PMN elevation effect (Oberdörster et al. 1994; Tran et al. 1999) (Fig. 5A) and lung tumor occurrence proportion (Lee et al., 1985; Heinrich et al., 1995) (Fig. 5B). The estimated median effective surface area-based $\mathrm{TiO}_{2}$ lung burden (EC50) for PMN elevation effect was $0.11 \mathrm{~m}^{2} \mathrm{~g}^{-1}$ lung (95\% CI: 0.04-0.2) and EC50 for lung tumor proportion was $1.15 \mathrm{~m}^{2} \mathrm{~g}^{-1}$ lung (95\% CI: 0.651.89). The estimated Hill coefficients $(n)$ obtained from optimal fitting by nonlinear regression were 2.1 for $\mathrm{TiO}_{2}-\mathrm{PMN}$ elevation effect and 5.32 for $\mathrm{TiO}_{2}$-lung tumor proportion relationships, indicating that the situation of $\mathrm{TiO}_{2}$ binding to receptors of lung cells was significant.

The EC10 value (a surrogate threshold of regulatory endpoint in probabilistic ecological risk assessment (USEPA, 2000)) of surface area-based $\mathrm{TiO}_{2}$ burden on PMN elevation effect (at which $10 \%$ of the animals are affected) calculated from the fitted dose-response model (Fig. 5A) was estimated to be $0.035 \mathrm{~m}^{2} \mathrm{~g}^{-1}$ lung with a $95 \%$ CI $0.016-0.074 \mathrm{~m}^{2} \mathrm{~g}^{-1}$ lung. On the other hand, the EC10 value of surface area-based $\mathrm{TiO}_{2}$ on lung tumor proportion was estimated to be $0.81 \mathrm{~m}^{2} \mathrm{~g}^{-1}$ lung (95\% CI: 0.48-1.39).

\subsection{Risk estimates}

No direct evidence reveals the relative sensitivity of the rats and humans to the carcinogenic effects of $\mathrm{TiO}_{2}$, but rats are no
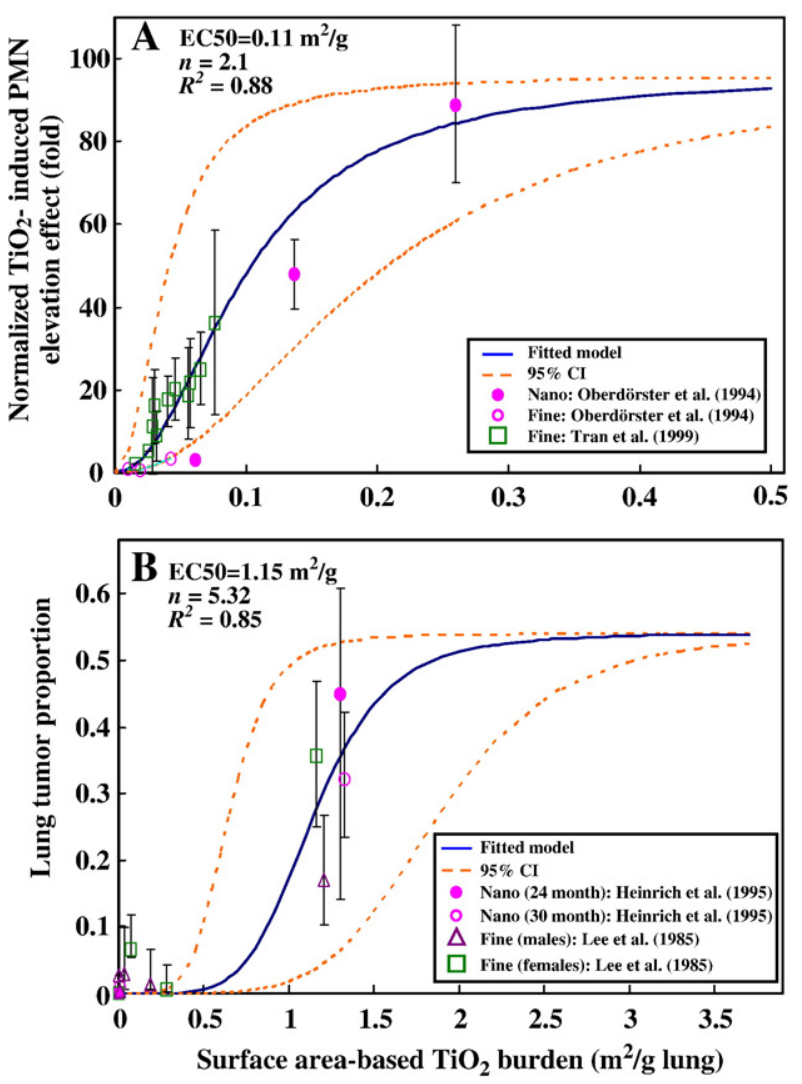

Fig. 5-Reconstructed Hill model-based dose-response profiles for (A) $\mathrm{TiO}_{2}$-induced PMN elevation effect and (B) lung tumor proportion. 
more sensitive to the carcinogenic effects caused by the known human carcinogens such as asbestos and crystalline silica than that of humans (NIOSH, 2005). Hsieh and Yu (1998) indicated that human lung clearance of particles is nearly an order of magnitude slower than that in rats. Moreover, in an extreme occupational setting, for example, coal miners may be exposed to concentrations resulting in doses that would be considered overloaded in rats (NIOSH, 2005). Thus, the doses that cause overloading in the rats may be relevant to estimate disease risk in workers with high dust exposures. On the other hand, the proposed dose-response profiles shown in Fig. 5 not only were statistically but also were significant pharmacodynamically associated with the total $\mathrm{TiO}_{2}$ particle surface area at all doses. This indicates that PMN elevation and lung tumor responses of $\mathrm{TiO}_{2}$ particles can be well predicted by particle surface area dose without the need to account for overloading (NIOSH, 2005). Therefore, in applying extrapolation of human surface-based $\mathrm{TiO}_{2}$ lung burden from rat-specific response experiments, it only takes into account the uncertainty factor $F_{3}=10$ for deriving a long-term EC from acute exposure tests.

Risk curves for the $\mathrm{TiO}_{2}$-induced $\mathrm{PMN}$ elevation effect (Fig. 6) indicate that the probabilities that $20 \%$ or more of production workers in US factories (risk $=0.2$ ) have approximately 94.36 fold (95\% CI: 67.96-94.63), 87.46 fold (95\% CI: 94.63-97.96), 51.61 fold (95\% CI: $20.71-85.11)$, and 4.51 fold (95\% CI: 1.11-32.91) of standard PMN counts of $10^{6}$, respectively, for packers, maintenance mechanics, dry/wet treatment, and ore handlers. In EU factories, for risk $=0.2$, the standard PMN counts $\left(10^{6}\right)$ will elevate at least to 94.8 fold (95\% CI: $91.48-$ 95.83) for surface treatment, 93.39 fold (95\% CI: 85.85-95.6) for

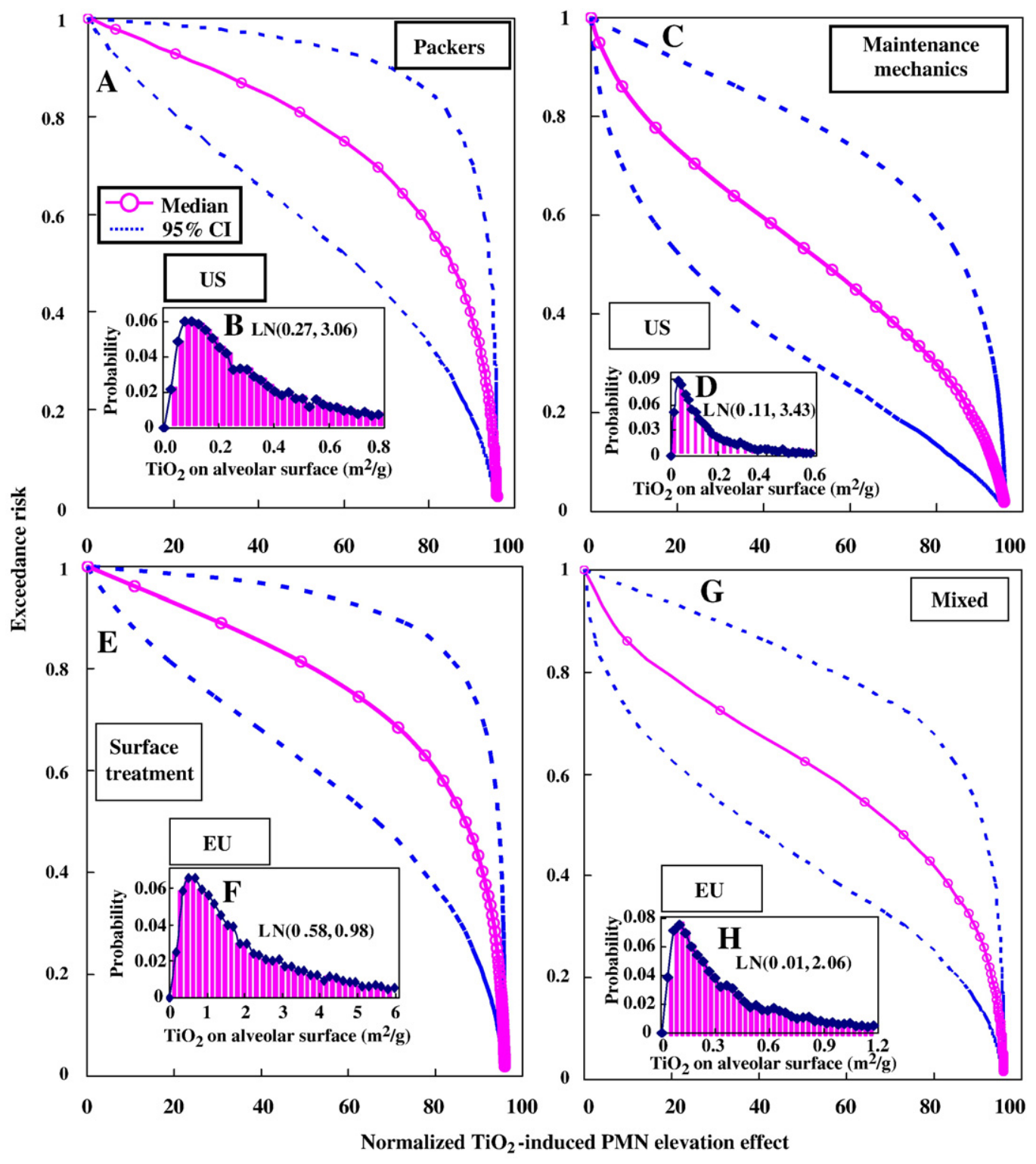

Fig. 6-Estimated exceedance risk curves with 95\% CI of PMN elevation effect for packer and maintenance mechanics workers in United States (A, C) and for surface treatment and mixed workers in Europe $(E, G)$ production factories based on the input probability density functions of $\mathrm{TiO}_{2}$ burden on alveolar surface followed a lognormal distribution (B, D, F, H). 

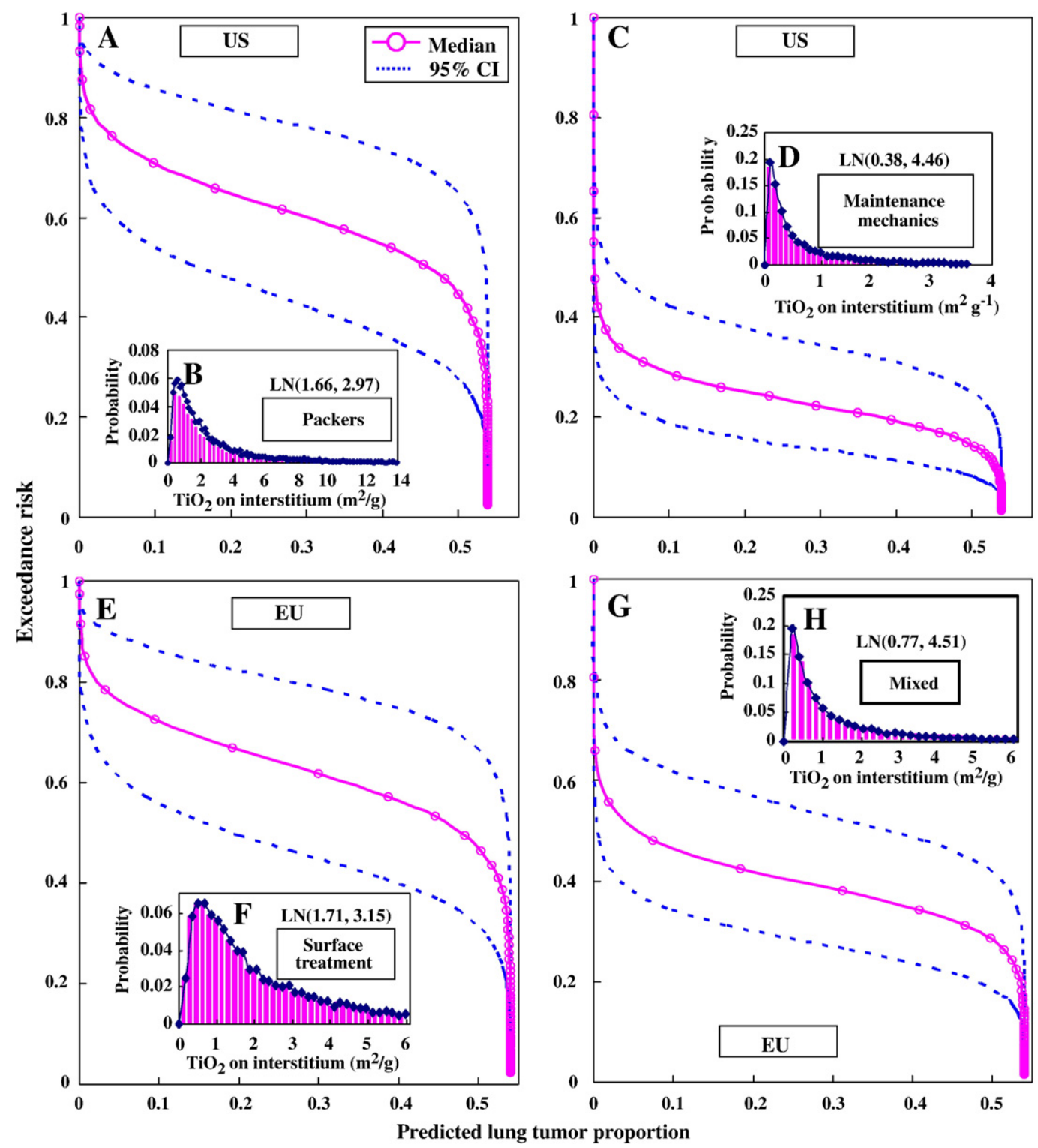

Fig. 7-Estimated exceedance risk curves with $95 \%$ CI of lung tumor proportion for packer and maintenance mechanics workers in United States (A, C) and for surface treatment and mixed workers in Europe (E, G) production factories based on the input probability density functions of $\mathrm{TiO}_{2}$ burden on interstitial granuloma followed a lognormal distribution (B, D, F, H).

mixed jobs, and 81.45 fold (95\% CI: 54.69-93.51) for maintenance mechanics.

Risk curves for the $\mathrm{TiO}_{2}$-induced lung tumor effect (Fig. 7) indicate that the risk $=0.5$ of production workers in US factories, the lung have approximately $45 \%$ (95\% CI: $15-54 \%)$, $0.19 \%$ (95\% CI: $0.01-3.63 \%$ ), and $0.08 \%$ (95\% CI: $0.01-1.7 \%$ ), respectively, for packers, maintenance mechanics, and dry/ wet treatment, suffering tumor responses. In EU factories, for the probability of 0.5 , at least $48.19 \%$ (95\% CI: $20-53.79 \%$ ) and $7.38 \%$ (95\% CI: 0.6-38.17\%) of lung tumor proportion will occur, respectively, for surface treatment and mixed jobs workers.

The risk estimates for the PMN elevation effect and predicted lung tumor proportion were based on the input job-specific $\mathrm{TiO}_{2}$ burden distributions, respectively, on alveo- lar surface (Fig. 6B,D,F,G) and on interstitial granuloma (Fig. 7B, $D, F, G)$. Table 4 summarizes the job-specific exceeding thresholds for the probabilities of lung tumor response and PMN elevation effect at risk of $0.2,0.5$, and 0.8 for $\mathrm{TiO}_{2}$ manufacturing workers in US and EU, respectively.

\section{Discussion}

\subsection{Hill-PB lung model}

The purpose of this model-based effort was to assess the potential inhalation risk for manufacturing workers in $\mathrm{TiO}_{2}$ production factories exposed to airborne nano/fine $\mathrm{TiO}_{2}$ dust. 
Table 4-Probability of lung tumor proportion and $\mathrm{TiO}_{2}$-induced $\mathrm{PMN}$ elevation effect for $\mathrm{TiO}_{2}$ manufacturing worker exceeding threshold (median with $95 \%$ CI)

Exceedance risk

\begin{tabular}{|c|c|c|c|c|c|c|}
\hline \multirow[t]{2}{*}{ Work setting } & 0.8 & 0.5 & 0.2 & 0.8 & 0.5 & 0.2 \\
\hline & \multicolumn{3}{|c|}{ Lung tumor proportion } & \multicolumn{3}{|c|}{$\mathrm{TiO}_{2}$-induced PMN elevation effect (fold) } \\
\hline \multicolumn{7}{|l|}{ US } \\
\hline Packers & $\begin{array}{l}0.0145 \\
(0.001-0.1973)\end{array}$ & $\begin{array}{l}0.45 \\
(0.15-0.54)\end{array}$ & $\begin{array}{l}0.5393 \\
(0.5296-0.54)\end{array}$ & $\begin{array}{l}49.55 \\
(19.35-84.25)\end{array}$ & $\begin{array}{l}85.77 \\
(63.84-94.33)\end{array}$ & $\begin{array}{l}94.36 \\
(67.96-94.63)\end{array}$ \\
\hline Maintenance mechanics & $\begin{array}{l}0.006 \\
(0.004-0.1031)\end{array}$ & $\begin{array}{l}0.0019 \\
(0.0001-0.0363)\end{array}$ & $\begin{array}{l}0.349 \\
(0.0618-0.5262)\end{array}$ & $\begin{array}{l}14.94 \\
(4.01-53.11)\end{array}$ & $\begin{array}{l}55.79 \\
(23.73-98.92)\end{array}$ & $\begin{array}{l}87.46 \\
(94.63-97.96)\end{array}$ \\
\hline Dry and wet treatment & $<10^{-4}$ & $\begin{array}{l}0.0008 \\
(0.0001-0.017)\end{array}$ & $\begin{array}{l}0.1897 \\
(0.0199-0.4961)\end{array}$ & $<10^{-3}$ & $<10^{-3}$ & $\begin{array}{l}51.61 \\
(20.71-85.11)\end{array}$ \\
\hline Ore handlers & $<10^{-4}$ & $<10^{-4}$ & $<10^{-4}$ & $\begin{array}{l}1.57 \\
(0.38-9.65)\end{array}$ & $\begin{array}{l}2.73 \\
(0.636-15.78)\end{array}$ & $\begin{array}{l}4.51 \\
(1.11-32.91)\end{array}$ \\
\hline Other jobs & $<10^{-4}$ & $<10^{-4}$ & $<10^{-4}$ & $\begin{array}{l}0.52 \\
(0.12-3.39)\end{array}$ & $\begin{array}{l}3.16 \\
(0.77-17.86)\end{array}$ & $\begin{array}{l}13.97 \\
(3.72-51.24)\end{array}$ \\
\hline \multicolumn{7}{|l|}{$E U$} \\
\hline Surface treatment & $\begin{array}{l}0.0328 \\
(0.0025-0.3136)\end{array}$ & $\begin{array}{l}0.4819 \\
(0.2-0.5369)\end{array}$ & $\begin{array}{l}0.5396 \\
(0.5343-0.54)\end{array}$ & $\begin{array}{l}49.12 \\
(19.07-84.06)\end{array}$ & $\begin{array}{l}86.97 \\
(66.72-94.54)\end{array}$ & $\begin{array}{l}94.8 \\
(91.48-95.83)\end{array}$ \\
\hline Mixed & $<10^{-4}$ & $\begin{array}{l}0.0738 \\
(0.006-0.3817)\end{array}$ & $\begin{array}{l}0.5357 \\
(0.485-0.5398)\end{array}$ & $\begin{array}{l}30 \\
(9.73-73.16)\end{array}$ & $\begin{array}{l}73.08 \\
(41.28-91.72)\end{array}$ & $\begin{array}{l}93.39 \\
(85.85-95.6)\end{array}$ \\
\hline Maintenance mechanics & $<10^{-4}$ & $<10^{-4}$ & $\begin{array}{l}0.0179 \\
(0.0001-0.226)\end{array}$ & $<10^{-3}$ & $<10^{-3}$ & $\begin{array}{l}81.45 \\
(54.69-93.51)\end{array}$ \\
\hline Other jobs & $<10^{-4}$ & $<10^{-4}$ & $\begin{array}{l}0.24 \\
(0.027-0.5096)\end{array}$ & $<10^{-3}$ & $\begin{array}{l}15.12 \\
(4.07-53.47)\end{array}$ & $\begin{array}{l}68.79 \\
(35.94-90.66)\end{array}$ \\
\hline
\end{tabular}

Unlike the modeling efforts with lung dosimetry and risk assessment of nanoparticles developed by Kuempel et al. (2006), a Hill model was used to reconstruct dose-response function based on data from rats exposed by chronic inhalation to poorly soluble fine and nanosized particles. This study used surface area-based $\mathrm{TiO}_{2}$ burdens in alveolar surface and interstitial granuloma, respectively, predicted from PB lung model as the biomarkers of exposure to relate the exposure characterized by PMN elevation effect on lung surface and lung tumor proportion on interstitium to exposures that may occurred chronically. The estimated median effective surfacebased $\mathrm{TiO}_{2}$ lung burden (EC50) for PMN elevation effect is $0.11 \mathrm{~m}^{2} \mathrm{~g}^{-1}$ lung (95\% CI: 0.04-0.2) and EC50 for lung tumor proportion is $1.15 \mathrm{~m}^{2} \mathrm{~g}^{-1}$ lung (95\% CI: 0.65-1.89). The estimates of risk curves in Figs. 6 and 7 are the pivotal results for public policy.

Fryzek et al. (2003) and Boffetta et al. (2004) both suggested that the workers exposures at US and $\mathrm{EU} \mathrm{TiO}_{2}$ production factories were not associated with a carcinogenic effect of $\mathrm{TiO}_{2}$ dust on the human lung based on a cohort mortality epidemiological study. However, NIOSH (2005) indicated that these epidemiological studies may have lacked the statistical strength to test an increased risk of mortality from $\mathrm{TiO}_{2}$ associated pneumoconiosis. The proposed Hill-PB lung model based risk analysis may compensate this disadvantage by using a scientifically based framework for the risk assessment for the substances that may be encountered in the workplace.

For example, the results demonstrate that the probabilities that $50 \%$ or more of packers in US factories have approximately 85.77 fold (95\% CI: 63.84-94.33) of standard PMN counts of $10^{6}$, whereas, in EU factories, the standard PMN counts $\left(10^{6}\right)$ will elevate at least to 86.97 fold (95\% CI: 66.72-94.54) for surface treatment workers. For the risk $=0.5$, the lung have approximately $45 \%$ (95\% CI: 15-54\%) of lung tumor proportion for packers in US plants, whereas, in EU factories, at least $48.19 \%$ (95\% CI: $20-53.79 \%$ ) of lung tumor proportion will occur for surface treatment (Table 4). More generally, the findings point out that dry/wet treatment, ore handlers, and other jobs workers in US plants and maintenance mechanics and other jobs workers in EU plants were unlikely to pose substantial lung cancer risk to public health given the most prevalent routes.

Packing is the last procedure of $\mathrm{TiO}_{2}$ products, and the powders of $\mathrm{TiO}_{2}$ are the smallest at this compartment in the process of product. Packers use drum changing operation (NIOSH, 2007) to pack $\mathrm{TiO}_{2}$ products, yet $\mathrm{TiO}_{2}$ could be emitted to working environment during the packing process. For this reason, the lung $\mathrm{TiO}_{2}$ burdens of packers are higher than that of other employee. The exposure risk of surface treatment setting (include drying, packing and blending) in the EU plants is two-fold higher than the packers in US plants. The exposure risk of maintenance mechanics employee in US and EU plants are not significantly different. Appropriate engineering control measures thus play an important role in limiting nano$\mathrm{TiO}_{2}$ dispersal in workplace environments.

The results also reveal that surface area matters more than mass for airborne nano/fine $\mathrm{TiO}_{2}$ dust. Because current sensors are limited, however, in their ability to detect surface area of particles in the nanosized range, this requires the development of appropriate surface area sampling devices. The published $\mathrm{TiO}_{2}$ dust exposure data employed in this study can not reflect the job- or process-specific particle size distribution effect on lung cancer risk (NIOSH, 2005). The nanoparticle size distribution affects the particle deposition and retention in human significantly (Oberdörster et al., 2005). Different size distributions should be existed in different work environments in the 
plants. Moreover, particle size distribution is inherently more accessible by practical sampling devices for NPs than particle compositions. Therefore, quantification of the job- or processspecific airborne fine and nano- $\mathrm{TiO}_{2}$ particle size distribution is worth to be considered to assess the internal dose for human exposure in the future study (NIOSH, 2005).

Recently, nanomaterials are emerging and noticeable issues association with the developing nanotechnology in the worldwide (Oberdörster et al., 2005). Yet the knowledge of nanomaterials is sparse and insufficient so far, especially for the transport, fate and causing effects of nanomaterials into human body (Oberdörster et al., 2002; Morgan, 2005; Nel et al., 2006). Several previously studies showed that the cellular uptake by macrophage is the major clearance mechanism when the particles reach into the alveolar-interstitial region (Moore and Willows, 1998; Donaldson et al., 2002; Borm et al, 2004; Oberdörster et al., 2005). However, the translocation effect is a common view to explain the particles penetration into other organ through blood and lymph circulation systems by most researchers (Morgan, 2005; Oberdörster et al., 2005; Nel et al., 2006). The nanomaterials causing the cellular interactions and toxicity is undoubtedly and need to further study.

Furthermore, the cellular interactions could lead to toxic responses when a cell is exposed to nanomaterials, and these toxic responses would induce cellular apoptosis/necrosis and cytotoxicity through multiple mechanisms (Nel et al., 2006; Unfried et al., 2007). The present study performed two endpoints, lung tumor proportion and PMN elevation effect, to describe the $\mathrm{TiO}_{2}$-induced adverse effects for susceptible groups in $\mathrm{TiO}_{2}$ manufacturer plants. Yet the possible cellular damages are always unknown. These related issues need more data to assess and overcome the knowledge gapes.

It recognized limitations in each of the data sources, particularly the inherent problem of uncertainty and variability of the data. The strength of these results rests on the robustness of the proposed Hill-PB lung model and the public and regulatory authorities' guideline values. The analysis may provide a wider context for the interpretation of regional $\mathrm{TiO}_{2}$ related lung cancer risk profiling that produced diverging and controversial outcomes, which has economic and policy implications. More complex models may be necessary to answer specific questions regarding risk or particular management strategies. However, the present simple model captures the essential risk analysis methodology and it's flexible enough to integrate effects occurring at varying job- or process-specific scales.

\subsection{Implications}

The risk-based theoretical treatments described herein give detailed mechanistic information but are challenging to apply directly to the analysis of experimental data.

Fortunately, simplified models have been developed to describe $\mathrm{TiO}_{2}$ particle uptake dynamics in lung tissues based on a physiological consideration, resulting in the reduction of the $\mathrm{TiO}_{2}$ burdens only taking into account on the alveolar surface and interstitial granuloma. This study proposed that the Hill model-based dose-response profiles and PB lung model approach, which amounts to $\mathrm{TiO}_{2}$-related lung cancer risk profiling, might provide the basis of a future population- based risk management strategy. Furthermore, this approach should have certain advantages over methods for dose response profiles selection that are dependent on the use of $\mathrm{TiO}_{2}$ animal models to characterize particular aspects of risk analysis.

A further inherent benefit of the Hill-PB lung model approach is to provide interplay among system approach, regulatory processes, and risk management. The main potential application for Hill-PB lung model approach is with respect to human health. There is clearly a need for further development and to investigate how well the approach can be transferred from $\mathrm{TiO}_{2}$ manufacturing factories to other environments, for which much greater chronic $\mathrm{TiO}_{2}$ exposure and environmental variation would be expected (Colvin, 2003; Lovern et al., 2007). Recent developments in data analysis should assist safe $\mathrm{TiO}_{2}$ exposure standard establishment and biomarkers identification of $\mathrm{TiO}_{2}$-related health hazards. Furthermore, extension of the $\mathrm{PB}$ lung model to a PB pharmacokinetic (PK) model to account for $\mathrm{TiO}_{2}$ translocation to organs beyond the lung is needed to provide an improved prediction of $\mathrm{TiO}_{2}$ burden for risk assessment (Kuempel et al., 2006). Therefore, metabolite profiling of fluids in PBPK model such as blood, urine, and fecal excretion, should provide additional information.

This study envisaged that optimal quantification of lung cancer risks from $\mathrm{TiO}_{2}$ dust exposure in $\mathrm{TiO}_{2}$ production plants may eventually involve a variety of dose response-prediction approaches. However, by linking Hill model-based doseresponse relationships and PB lung model has an important theoretical advantage over traditional models. It can potentially take account of both physiological and occupational factors affecting $\mathrm{TiO}_{2}$-related adverse health responses. Furthermore, although the proposed framework would normally relate to predicting safe $\mathrm{TiO}_{2}$ dust exposure level and the likelihood of risk estimates, it envisaged that similar methodology could be applied to predicting potential populationlevel long-term low dose pre-cancerous and cancer risk responses to broader medical, dietary, microbiological or physiological challenges (Geiser et al., 2005; Limbach et al., 2007; Lovern et al., 2007).

\section{Conclusions}

In this study, a Hill model was used to reconstruct doseresponse function. A PB lung model was used to predict the biomarkers of exposure. The predicted surface area-based $\mathrm{TiO}_{2}$ burdens in alveolar surface and interstitial granuloma were characterized by lung PMN elevation effect and tumor proportion. Results indicate that packers in US factories had 85.77 fold of standard PMN counts of $10^{6}$, whereas 86.97 fold for surface treatment workers in EU factories at risk of 0.5 . The lung had approximately $45 \%$ tumor proportion for packers in US factories, whereas $48.19 \%$ for surface treatment workers in EU factories at risk of 0.5 . The dry/wet treatment and ore handlers in US and maintenance mechanics in EU factories were unlikely to pose substantial lung cancer risks. This study may help to inform public and regulatory authorities on discussions of risk management and communication by drawing attention to the worldwide nanotoxicology issues 
on human health. The factory managers were encouraged to formulate and implement their own risk management plans based on this proposed model-based approach.

\section{R E F E R E N C E S}

Baan R, Straif K, Grosse Y, Secretan B, Ghissassi FE, Cogliano V. Carcinogenicity of carbon black, titanium dioxide, and talc. Lancet Oncol 2006;7:296-295.

Berges M, Mohlmann C, Swennen B, van Rompaey Y, Berghmans P. Workplace exposure characterization at $\mathrm{TiO}_{2}$ nanoparticle production. 3rd International Symposium on Nanotechnology, Occupational and Environmental Health, Aug. 29 to Sept. 1, 2007, Taipei, Taiwan; 2007.

Boffetta P, Gaborieau V, Nadon L, Parent ME, Weiderpass E, Siemiatycki J. Exposure to titanium dioxide and risk of lung cancer in a population-based study from Montreal Scand. J Work Environ Health 2001;27:227-32.

Boffetta P, Soutar A, Weiderpass E, Cherrie J, Granath F, Andersen A, et al. Historical cohort study of workers employed in the titanium dioxide production industry in Europe. Results of mortality follow-up. Final report. Department of Medical Epidemiology. Stockholm: Karolinska Institutet; 2003.

Boffetta P, Soutar A, Cherrie JW, Granath F, Andersen A, Anttila A, et al. Mortality among workers employed in the titanium dioxide production industry in Europe. Cancer Causes Control 2004;15:697-706.

Borm PJA, Schins RPF, Albrecht C, Albrecht C. Inhaled particles and lung cancer, part B: paradigms and risk assessment. Int J Cancer 2004;110:3-14.

Chen JL, Fayerweather WE. Epidemiologic study of workers exposed to titanium dioxide. J Occup Environ Med 1988;30:937-42.

Colvin VL. The potential environmental impact of engineered nanomaterials. Nat Biotechnol 2003;21:1166-70.

Donaldson K, Tran CL. Inflammation caused by particles and fibers. Inhal Toxicol 2002;14:5-27.

Donaldson K, Broan D, Clouter A, Duffin R, MacNee W, Renwick L, et al. The pulmonary toxicology of ultrafine particles. J Aerosol Med-Depos Clear Eff Lung 2002;15:213-20.

Donaldson K, Stone V, Tran CL, Kreyling W, Borm PJA. Nanotoxicology. Occup Environ Med 2004;61:727-8.

Dourson ML, Stara JF. Regulatory history and experimental support of uncertainty (safety) factors. J Reg Toxicol Pharmacal 1983;3:224-38.

Fayerweather WE, Karns ME, Gilby PG, Chen JL. Epidemiologic study of lung cancer mortality in workers exposed to titanium tetrachloride. J Occup Environ Med 1992;34:164-9.

Fryzek JP, Chadda B, Marano D, White K, Schweitzer S, McLaughlin $\mathrm{JK}$, et al. A cohort mortality study among titanium dioxide manufacturing workers in the United States. J Occup Environ Med 2003;45:400-9.

Geiser M, Rothen-Rutishauser B, Kapp N, Schürch S, Kreyling W, Schulz H, et al. Ultrafine particles cross cellular membranes by nonphagocytic mechanisms in lungs and in cultured cells. Environ Health Perspect 2005;113:1555-60.

Heinrich U, Fuhst R, Rittinghausen S, Creutzenberg O, Bellmann B, Koch W, et al. Chronic inhalation exposure of Wistar rats and 2 different strains of mice to diesel-engine exhaust, carbon black, and titanium dioxide. Inhal Toxicol 1995;7:533-56.

Hsieh TH, Yu CP. Two-phase pulmonary clearance of insoluble particles in mammalian species. Inhal Toxicol 1998;10:121-30.

Höhr D, Steinfartz Y, Schins RPF, Knaapen AM, Martra G, Fubini B, et al. The surface area rather than the surface coating determines the acute inflammatory response after instillation of fine and ultrafine $\mathrm{TiO}_{2}$ in the rat. Int J Hyg Environ Health 2002;205:239-44.

IARC. Titanium dioxide Group 2B. vols.9. Monographs on the evaluation of carcinogenic risks to humans. International Agency for Research on Cancer. Lyon: World Health Organization; 2006.

Inoue $\mathrm{K}$, Takano H, Yanagisawa R, Ichinose T, Sakurai M, Yoshikawa T. Effects of nano particles on cytokine expression in murine lung in the absence or presence of allergen. Arch Toxicol 2006;80:614-9.

Kuempel ED, Tran CL, Smith RJ, Bailer AJ. A biomathematical model of particle clearance and retention in the lungs of coal miners. II Evaluation of variability and uncertainty. Regul Toxicol Pharmacol 2001;34:88-101.

Kuempel ED, Tran CL, Castranova V, Bailer AJ. Lung dosimetry and risk assessment of nanoparticles: evaluating and extending current models in rats and humans. Inhal Toxicol 2006;18:717-24.

Lee KP, Trochimowicz HJ, Reinhardt CF. Pulmonary response of rats exposed to titanium dioxide $\left(\mathrm{TiO}_{2}\right)$ by inhalation for two years. Toxicol Appl Pharmacol 1985;79:179-92.

Limbach LK, Wick P, Manser P, Grass RN, Bruinink A, Stark WJ. Exposure of engineered nanoparticles to human lung epithelial cells: influences of chemical composition and catalytic activity on oxidative stress. Environ Sci Technol 2007;41:4158-63.

Lovern SB, Strickler JR, Klaper R. Behavioral and physiological changes in Daphnia magna when exposed to nanoparticle suspensions (titanium dioxide, Nano- $\mathrm{C}_{60}$, and $\mathrm{C}_{60} \mathrm{H}_{\mathrm{x}} \mathrm{C}_{70} \mathrm{H}_{\mathrm{x}}$ ). Environ Sci Technol 2007;41:4465-70.

Maynard AD, Aitken RJ. Assessing exposure to airborne nanomaterials: current abilities and future requirements. Nanotoxicol 2007;1:26-41.

Maynard AD, Aitken RJ, Butz T, Colvin V, Donaldson K, Oberdörster $\mathrm{G}$, et al. Safe handling of nanotechnology. Nature 2006;444:267-9.

Moore MN, Willows RI. A model for cellular uptake and intracellular behaviour of particulate-bound micropollutants. Mar Environ Res 1998;46:509-14.

Morgan K. Development of a preliminary framework for informing the risk analysis and risk management of nanoparticles. Risk Anal 2005;25:1621-35.

$\mathrm{Nel} \mathrm{A.} \mathrm{Air} \mathrm{pollution-related} \mathrm{illness:} \mathrm{effects} \mathrm{of} \mathrm{particles.} \mathrm{Science}$ 2005;306:804-6.

Nel A, Xia T, Mädler L, Li N. Toxic potential of materials at the nanolevel. Science 2006;311:622-7.

Nemmar A, Hoet PHM, Vanquickenborne B, Dinsdale D, Thomeer M, Hoylaerts MF, et al. Passage of inhaled particles into the blood circulation in humans. Circulation 2002;105:411-4.

Nemmar A, Hoylaerts MF, Hoet PHM, Vermylen J, Nemery B. Size effect of intratracheally instilled particles on pulmonary inflammation and vascular thrombosis. Toxicol Appl Pharmacol 2003;186:38-45.

NIOSH. NIOSH current intelligence bulletin: evaluation of health hazard and recommendations for occupational exposure to titanium dioxide. Draft. Department of Health and Human Services. Public Health Service. Centers for Disease Control and Prevention. National Institute for Occupational Safety and Health. Cincinnati: DHHS (NIOSH) publication; 2005.

NIOSH. Progress toward safe nanotechnology in the workplace. Department of Health and Human Services. Public Health Service. Centers for Disease Control and Prevention. National Institute for Occupational Safety and Health. Cincinnati: DHHS (NIOSH) publication; 2007.

Oberdörster G, Ferin J, Lehnert BE. Correlation between particle size, in vivo particle persistence, and lung injury. Environ Health Perspect 1994;102(Suppl 5):173-9. 
Oberdörster G, Sharpm Z, Atudorei V, Elder A, Gelein R, Lunts A, et al. Extrapulmonary translocation of ultrafine carbon particles following whole-body inhalation exposure of rats. J Toxicol Environ Health 2002;65:31-1543.

Oberdörster G, Oberdörster E, Oberdörster J. Nanotoxicology: an emerging discipline evolving from studies of ultrafine particles. Environ Health Perspect 2005;113:823-39.

Stoeger T, Reinhard C, Takenaka S, Schroeppel A, Karg E, Ritter B, et al. Instillation of six different ultrafine carbon particles indicates a surface area threshold dose for acute lung inflammation in mice. Environ Health Perspect 2006;114:328-33.

Tran CL, Jones A, Cullen RT, Donaldson K. Mathematical modeling of the retention and clearance of low-toxicity particles in the lung. Inhal Toxicol 1999;11:1059-76.

Tran CL, Buchanan D, Jones AD. Mathematical modeling to product the response to poorly soluble particle in rat lungs. Inhal Toxicol 2000;12(Suppl 3):403-9.

Tran CL, Jones AD, Miller GB, Donaldson K. Modeling the retention and clearance of manmade vitreous fibers in the rat lung. Inhal Toxicol 2003;15:553-87.
Tsuji JS, Maynard AD, Howard PC, James JT, Lam CW, Warheit DB, et al. Research strategies for safety evaluation of nanomaterials, Part IV Risk assessment of nanoparticles. Toxicol Sci 2006;89:42-50.

Unfried K, Albrecht C, Klotz LO, Mikecz AV, Grether-Beck S, Schins RPE. Cellular responses to nanoparticles: target structures and mechanisms. Nanotoxicol 2007;1:52-71.

USEPA. Guidance Manual for the Integrated Exposure Uptake Biokinetic Model for Lead in Children, EPA/540/E-93/081. Washington, DC: Office of Solid Waste and Emergency Response; 1994.

USEPA. Technical progress report of the implementation plan for probabilistic ecological assessments: aquatic systems. Meeting scheduled for April 6-7. Washington, DC: US Environmental Protection Agency; 2000.

Wittmaack K. In search of the most relevant parameter for quantifying lung inflammatory response to nanoparticle exposure: particle number, surface area, or what? Environ Health Perspect 2007;115:187-94. 